\title{
Responsive Behavior of 4-(N-maleimido)azobenzene in Polymers with Aromatic Main Chain and Side Chain Linked Units
}

\author{
Anton Airinei, * Elena Rusu and Virgil Barboiu \\ Petru Poni Institute of Macromolecular Chemistry, Romanian Academy, Aleea Grigore Ghica Voda, \\ 41A, 700487 Iasi, Romania
}

\begin{abstract}
Matrizes poliméricas com cadeia principal aromática e cadeias laterais formadas por unidades de poliestireno e polissulfona foram empregadas para construir filmes finos contendo moléculas de maleimidoazobenzeno, a fim de desenvolver novos materiais com propriedades responsivas. $\mathrm{O}$ comportamento fotocrômico do composto ativo foi estudado no estado sólido e em solução, para comparação. A isomerisação térmica cis-trans de cromóforos de azobenzeno em filmes finos de polímeros segue duas etapas cinéticas diferentes. Um processo de relaxação de segunda ordem (rápido e lento) ocorre em matriz de poliestireno abaixo de $70^{\circ} \mathrm{C}$, enquanto a isomerização térmica a $70^{\circ} \mathrm{C}$ ou em temperatura mais alta segue cinética de primeira ordem. A quantidade de isômero cis correspondente ao estado fotoestacionário foi mais baixa em filmes do polímero do que em solução.
\end{abstract}

Polymer matrices with aromatic main chain and side chain linked units (polystyrene, polysulfone) were employed to construct thin films containing maleimidoazobenzene molecules in order to develop new materials with responsive properties. The photochromic behavior of the active compound was studied both in the solid and solution state for comparison. The thermal cistrans isomerization of azobenzene chromophores in polymer films follows two different kinetic pathways. A double-exponential relaxation process (fast and slow) took place in polystyrene matrix under $70{ }^{\circ} \mathrm{C}$ while the thermal isomerization at $70^{\circ} \mathrm{C}$ and higher follows a first-order kinetics. The cis isomer content corresponding to the photostationary state was found to be lower in polymer films than in solution.

Keywords: azobenzene, photoisomerization, UV-Vis spectroscopy, thin polymer film

\section{Introduction}

One of the most interesting and studied systems that can respond to changes in environmental conditions are those that contain the azobenzene chromophores. Their potential use in optics or optoelectronics, such as for information storage, optical switching devices, surface relief gratings, nonlinear optics, etc has been motive the attention of the researchers and end users. ${ }^{1-10}$ Large area of applications of azobenzene compounds is possible due to both its photoinduced properties and wide variety of the systems that it contained. Azobenzene chromophore has unique optical and photochemical properties. It undergo a reversible well know process with wide importance in pure and applied chemistry and in nature, namely trans-to-cis isomerization. This fundamental process can be controlled by both light and thermal relaxation. So, irradiated with

\footnotetext{
*e-mail: airineia@icmpp.ro
}

appropriate UV light, the stable trans form of azobenzene and its derivatives can be converted to the metastable cis form. As response to irradiation with visible light or thermal treatment in dark cis isomer will subsequently relax back to the trans state. Moreover, associated photoisomerization processes can take place and thus some of its properties can be controlled. During the trans-cis-trans isomerization processes significant changes of properties like the radiation absorption, molecular dimensions and dipole moment occur. ${ }^{1,11,12}$ The incorporation of photochromic moieties in solid polymers has been explored in order to obtain new photoresponsive materials and optical devices. Several approaches were used to insert azobenzene chromophores into polymer matrices: randomly incorporation (guest-host structures), binding to main or side chains, or formation of thin-layer structures like Langmuir-Blodgett films. ${ }^{2-5,13-15}$ Azobenzene-containing polymers have been investigated with regard to different phenomena associated with the photochromic nature of the azobenzene moiety. Their 
conformational modifications induced by photo- or thermal isomerization of the azobenzene chromophore give the possibility to control some physical and chemical properties of the materials including viscosity, solubility, $\mathrm{pH}$, refractive index, conductivity, dielectric permittivity, mechanical properties, etc. ${ }^{1-3,12,16}$

Doping azobenzene compounds into polymer matrices is a convenient inclusion technique. Besides opportunity to use a presynthetized polymer the development of doped azobenzene systems become interesting for studying the behavior of chromophore and owing to the actual tendency to obtain composites with very small content of active component. A variety of polymers and azobenzene compounds is possible to be used. The choosing of a polymer is related to its film forming ability because for many practical applications is of interest to use solid films. On other hand it is necessary to take into account solubility of azobenzene compounds in order to obtain homogeneous and transparent films. Although it is known that the nature and morphology of a polymer influence the photophysical and photochemical behavior of a chromophore incorporated in a polymer matrix, the way in which a photochromic process is influenced by polymer properties is not completely explained. The isomerization reactions in solid state may be different from those in solution due to the influence of the free volume local distribution in the matrix and the restrictions of chain mobility. For example, a non-first-order progress of the reaction is frequently observed in solid state. The thermal cistrans isomerization of azobenzene groups is characterized by first-order kinetics for polymers in solution or above their glass transition temperature. On the other hand, deviations from the first-order kinetics were found for the thermal relaxation of azobenzene moities in polymer matrices in glassy state. In this case the thermal back process has been described by two or three exponentials ${ }^{3,12,17,18}$ or by the Kohlrausch-Williams-Watt stretched exponential model. ${ }^{19}$

In the fundamental and applied chemistry maleimide derivatives are placed on an important place. Due to their dienophilic nature (Diels-Alder reaction, "click chemistry"), reactivity in Michael-addition reactions (especially for located $\mathrm{S}$ atoms in the protein and peptide structures), ability to undergo photocycloaddition, polymerization and crosslinking reactions this type of compounds is widely employed as substrates in chemical and biological applications. The electron-withdrawing nature of the two carbonyl groups present in their structure generate a very electron-deficient double bond, that than explicate the reactivity of maleimides. ${ }^{20}$

In the present paper the photochromic behavior and the kinetics of trans-cis-trans isomerization of low-molecular weight azobenzene chromophores in polymer matrixes will be discussed. Two commercial polymers were chosen as matrix component of the systems under study. One was polystyrene that has a long hydrocarbon chain, with a phenyl group attached to every other carbon atom. The other polymer matrix was polysulfone that contains aromatic moieties along polymer chains. The two polymers are well known for their ability to form photostable transparent films. Despite the fact that polysulfone is a high performance polymer and widely used in the preparation of the membranes and composites its application as matrix for azobenzene chromophores lacks in the literature. The azobenzene compound, 4-(N-maleimido) azobenzene belongs to the azobenzene spectroscopic first class, as described Rau. ${ }^{12}$ The photoresponsive behavior of the 4-(N-maleimido)azobenzene in polymer matrix was compared with that observed in dilute solution. The kinetic parameters were evaluated from the temporal evolution of $\pi-\pi^{*}$ absorption band intensity and the results were presented herein.

\section{Experimental}

\section{Equipment and reagents}

Electronic absorption spectra were obtained on a SPECORD M42 Carl Zeiss Jena spectrophotometer. Samples as polymer films and as chloroform solutions using $10 \mathrm{~mm}$ quartz cells fitted with poly(tetrafluoroethylene) stoppers were investigated. The initial absorbance in the case of the solution samples was taken between 0.8 and 1.0.

The photochromic experiments were carried out at room temperature using a 350 medium pressure mercury arc lamp and suitable glass filters were used to obtain the irradiation light. An intensity of 40-45 $\mathrm{W} \mathrm{m}^{-2}$ for $365 \mathrm{~nm}$ radiation was as a rule used. The polymer films were prepared on quartz supports by casting from dichloroethane solution by mixing equal portions of a $5 \mathrm{wt} \%$ polymer solution and a $0.2 \mathrm{wt} \%$ solution of low-mass azobenzene. The films were dried under reduced pressure at $50{ }^{\circ} \mathrm{C}$ for $24 \mathrm{~h}$. The thickness of the films was about $120 \mu \mathrm{m}$. The thermal relaxation of the samples under study was followed by monitoring the temporal modification of the absorbance corresponding $\pi-\pi^{*}$ transition at constant temperature. The reverse cistrans isomerization was also observed by irradiation with $436 \mathrm{~nm}$ visible light.

\section{Synthesis of 4-(N-maleimido)azobenzene (MAz)}

Maleic anhydride (Fluka) was purified by distillation. 4-Aminoazobenzene (Merck) was used as received. Chloroform (Merck) was spectrophotometric grade. All other chemicals were used as supplied. Polystyrene 
(Aldrich, $\mathrm{M}_{\mathrm{w}}=42$ 500) and polysulfone UDEL 1700 (Union Carbide, $\mathrm{M}_{\mathrm{w}}=38000$ ) were used as host polymers.

The guest component was prepared as follows:

To a well stirred solution of maleic anhydride $(15 \mathrm{mmol}$, $1.47 \mathrm{~g}$ ) in $10 \mathrm{~mL}$ of dry acetone, 4-aminoazobenzene $(15 \mathrm{mmol}, 2.96 \mathrm{~g})$ dissolved in dry acetone $(15 \mathrm{~mL})$ was added under nitrogen over a period of $20 \mathrm{~min}$ at ice bath temperature. After complete addition, the reaction mixture was stirred for $3 \mathrm{~h}$ at room temperature. The insoluble maleamic acid was separated by filtration, washed with acetone and then added to a solution of sodium acetate in acetic anhydride $(30 \mathrm{~mL}, 0.025 \mathrm{~mol})$ in order to cyclize to the corresponding maleimide. The reaction was conducted under nitrogen at $80{ }^{\circ} \mathrm{C}$ for $4 \mathrm{~h}$. The mixture was poured into a saturated aqueous solution of $\mathrm{NaHCO}_{3}$ and then the precipitate was washed three times with water and dried at $50{ }^{\circ} \mathrm{C}$ under vacuum. Pure MAz was obtained as a bright orange crystalline solid after recrystalization from chloroform. Yield 85\%; mp $169^{\circ} \mathrm{C}$.

Nitrogen analysis calculated for $\mathrm{C}_{16} \mathrm{H}_{11} \mathrm{~N}_{3} \mathrm{O}_{2}: \mathrm{N}$, $15.15 \%$. Found: N, $15.10 \%$.

${ }^{1} \mathrm{H}$ NMR (DMSO-d $) \delta(\mathrm{ppm}): 7.25(\mathrm{~s}, 2 \mathrm{H}, \mathrm{CH}=\mathrm{CH})$, 7.6-7.7 (m, 5H, Ar), 7.95 (d, 2H, Ar, adjacent to azo), 8.05 (d, $2 \mathrm{H}, \mathrm{Ar}$, adjacent to imide).

\section{Results and Discussion}

The guest compound of $\mathrm{N}$-substituted maleimide type was prepared by reacting 4-amino azobenzene with maleic anhydride. On the first stage of the reaction, maleic anhydride dissolved in acetone was condensed at room temperature with 4-aminoazobenzene (in equimolar amounts) to give azobenzenemaleanilic acid and then the anhydride cycle was reformed in the presence of acetic anhydride at $80^{\circ} \mathrm{C}$. The synthetic procedure of azoactive compound is illustrated in Scheme 1.

\section{Photoisomerization of 4-(N-maleimido)azobenzene molecules in solution}

Ultraviolet visible absorption spectroscopy was utilized in order to investigate the photoisomerization behavior of the azobenzene moieties. Figure 1 shows the absorption spectra of 4-(N-maleimido)azobenzene (MAz) recorded at several values of the irradiation time. The appearance of a strong absorption band centered at around $327 \mathrm{~nm}$ and another absorption band of low intensity at around $440 \mathrm{~nm}$ is evidenced in chloroform solution. These new absorption bands can be assigned to the $\pi-\pi^{*}$ and $n-\pi^{*}$ electronic transitions of the azobenzene chromophore. ${ }^{1,11,12}$ Under $365 \mathrm{~nm}$ irradiation the intensity of the $\pi-\pi^{*}$ absorption band gradually decreased with the irradiation time, while that of the $n-\pi^{*}$ absorption band increased. Simultaneously, the absorption maximum of $\pi-\pi^{*}$ band is slightly shifted to shorter wavelengths because the molecular conjugation decreases when the cis content increases. The two typical isosbestic points observed at around 285 and $390 \mathrm{~nm}$, respectively, confirms that only two absorbing species were present in the reaction medium, namely trans and cis isomers of maleimidoazobenzene. The trans-cis photoreaction reached a stationary state after $c a .15$ min of irradiation, when the cis fraction is about 0.70 .

The photoisomerization kinetics of azobenzene chromophores in MAz was established by monitoring the absorbance of $\pi-\pi^{*}$ absorption band. The experimental data were analysed according to the equation: ${ }^{21}$

$\ln \left(\mathrm{A}_{\mathrm{o}}-\mathrm{A}_{\infty}\right) /\left(\mathrm{A}_{\mathrm{t}}-\mathrm{A}_{\infty}\right)=\mathrm{k}_{1} \mathrm{t}$

where $\mathrm{t}$ is the irradiation time, $\mathrm{A}_{\mathrm{o}}, \mathrm{A}_{\mathrm{t}}$ and $\mathrm{A}_{\infty}$ are the trans form absorbances corresponding to the time $0, \mathrm{t}$ and photostationary state, respectively. The rate constant $\mathrm{k}_{1}$ has the expression $\mathrm{k}_{1}=\mathrm{k}_{\mathrm{tc}}+\mathrm{k}_{\mathrm{ct}}=\mathrm{I}\left(\phi_{\mathrm{tc}} \varepsilon_{\mathrm{t}}+\phi_{\mathrm{ct}} \varepsilon_{\mathrm{c}}\right) \ln 10$, where $\mathrm{k}_{\mathrm{tc}}$ and $\mathrm{k}_{\mathrm{ct}}$ are the rate constants for the trans-cis and cis-trans photoisomerization reactions, respectively, $\phi_{\mathrm{tc}}$ and $\phi_{\mathrm{ct}}$ are the quantum yields of the same processes, $\varepsilon_{\mathrm{t}}$ and $\varepsilon_{\mathrm{c}}$ are the molar absorptivities of the trans and cis species at the irradiation wavelength, and $\mathrm{I}$ is the incident radiation intensity. The plots of $\ln \left(A_{0}-A_{\infty}\right) /\left(A_{t}-A_{\infty}\right)$ versus irradiation time were linear for all samples (solution and film) as shown in Figure 2. A value of $6.37 \times 10^{-3} \mathrm{~s}^{-1}$ was obtained for the rate constant $\left(\mathrm{k}_{1}\right)$ for photoisomerization of azobenzene moieties in MAz in chloroform solution.

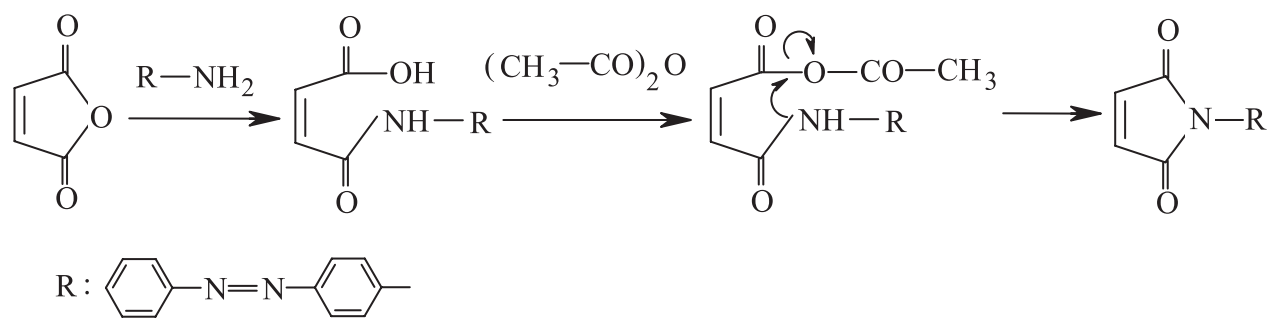

Scheme 1. Synthesis of maleimidoazobenzene derivative. 


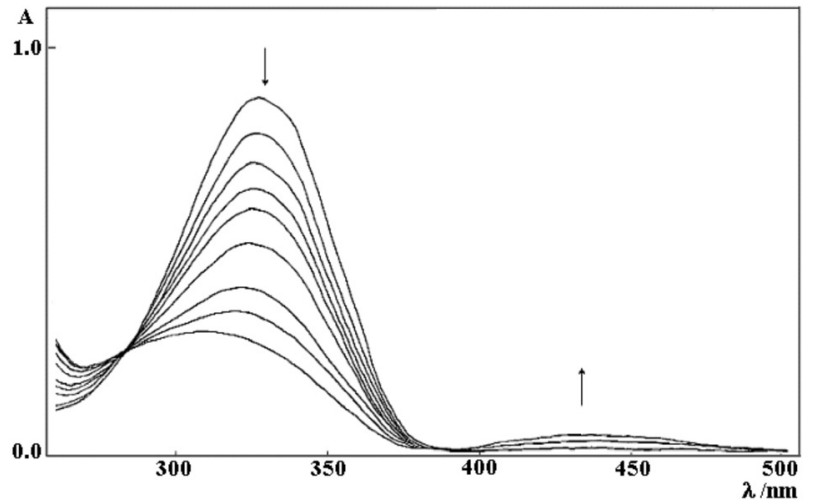

Figure 1. Change in electronic absorption spectra during trans-cis photoisomerization of 4-(N-maleimido)azobenzene. Arrows indicate the directional changes of the spectra. Irradiation times: 0, 30, 60, 90, 120, $180,300,420,900 \mathrm{~s}$

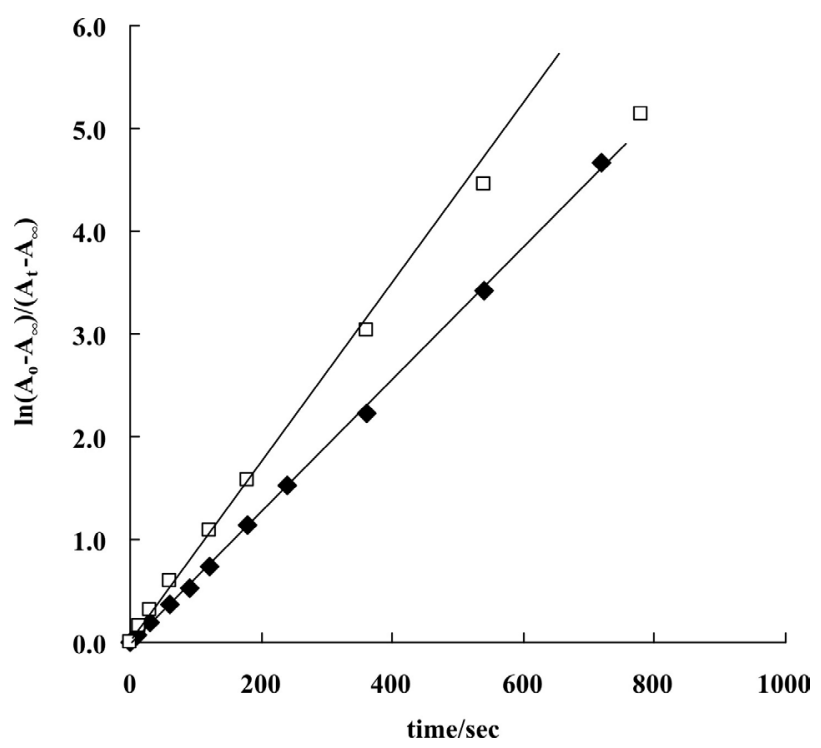

Figure 2. Photoisomerization kinetics for MAz in solution ( $\square$ ) and in polystyrene matrix ( $\square$ ).

\section{Thermal cis-trans isomerization in solution}

In the dark, the cis isomer slowly reverted to the original trans form that is thermodynamically more stable. The absorption spectrum gradually recovered to the before irradiation pattern. The thermal back isomerization was monitored at several temperatures and the results are shown in Figure 3 for $\mathrm{MAz}$, at $60{ }^{\circ} \mathrm{C}$. The absorption band at $327 \mathrm{~nm}$ increased in intensity to the starting value before irradiation. The retention of isosbestic points shows that a real cis-trans isomerization occurs thermally. The cycle of trans-cis photoisomerization and cis-trans isomerization can be repeated several times without significant modification in the intensity of $\pi-\pi^{*}$ absorption band.

It is known that the thermal cis-trans isomerization of azo species follows first-order kinetics. ${ }^{22,23}$ The kinetic equation in this case should be:

$$
\ln \left(A_{\infty}-A_{o}\right) /\left(A_{\infty}-A_{t}\right)=k_{2} t
$$

where $\mathrm{k}_{2}$ is the rate constant of the recovery reaction. The value of $\mathrm{k}_{2}$ for $\mathrm{MAz}$ was found $3.33 \times 10^{-5} \mathrm{~s}^{-1}$ at $50{ }^{\circ} \mathrm{C}$. From the Arrhenius plot of the rate constants, the following values of activation energy and the preexponential factor were evaluated: $\mathrm{E}_{\mathrm{a}}=18.06 \mathrm{kcal} \mathrm{mol}^{-1}$ and $\mathrm{Z}=6.3 \times 10^{7} \mathrm{~s}^{-1}$. The value found for the activation energy of cis-trans isomerization of $\mathrm{MAz}$ is rather similar to those of other azobenzene compounds. ${ }^{11,23-26}$

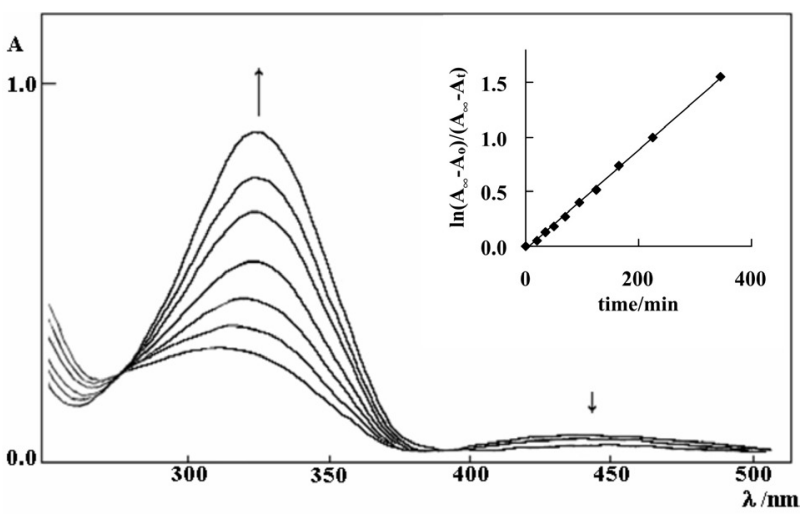

Figure 3. Variation of UV-Vis spectra of MAz during the thermal relaxation process at $60{ }^{\circ} \mathrm{C}$. Inlet: Cis-trans isomerization kinetics in solution. Arrows indicate the directional changes of the spectra. Relaxation times: $0,35,70,125,225,345,585 \mathrm{~min}$.

\section{Photoisomerization in polymer matrix}

As known, the isomerization reactions of azobenzene chromophores in rigid media depend very much on the local environment and free volume distribution around the chromophores. $^{27-29}$

Figure 4 illustrates the changes in the electronic absorption spectra of the 4-(N-maleimidoazobenzene) dispersed in polystyrene during irradiation with UV radiation of $360 \mathrm{~nm}$. One can see that the polymer films exhibit similar absorption maxima as liquid samples, namely at around 333 and $440 \mathrm{~nm}$, assigned to the $\pi-\pi^{*}$ and $n-\pi^{*}$ transitions, respectively. The $\pi-\pi^{*}$ absorption band decreases in intensity with the irradiation time due to the trans-cis photoisomerization process of azobenzene moieties. A photostationary state is reached after $20 \mathrm{~min}$ when the conversion is about $60 \%$. As in the case of liquid samples, there are isosbestic points on the both sides of the $\pi-\pi^{*}$ absorption band, and the absorption maximum shifted to shorter wavelengths. It is to be noticed that the cis content of the stationary state was a little lower in polymer film than in solution. A photoisomerization inhibition should be expected in solid samples because the free volume around the chromophore is smaller than in liquid samples due to a closer packing of the polymer chains in film. 


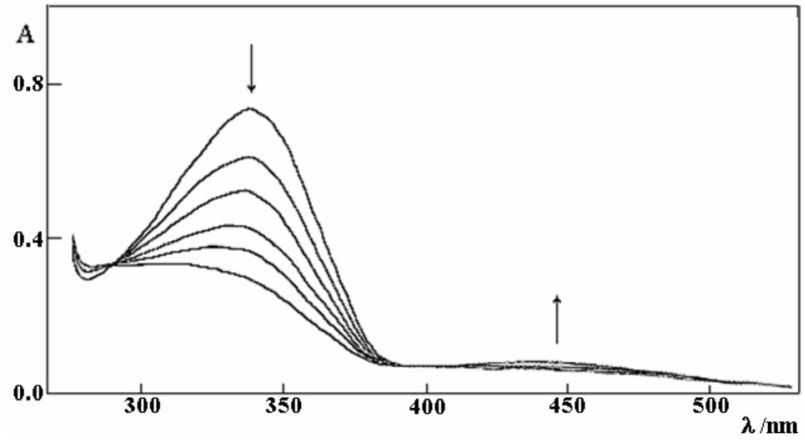

Figure 4. Spectral changes during trans-cis photoisomerization for a polymer film containing maleimidoazobenzene. Arrows indicate the directional changes of the spectra. Irradiation times: $0,30,60,120,180$, $540 \mathrm{~s}$.

The change in absorbance of the $\pi-\pi^{*}$ band during UV irradiation is consistent with a first-order process (Figure 2). The rate constant $\left(\mathrm{k}_{1}\right)$ for the azochromophore photoisomerization was found to be $8.34 \times 10^{-3} \mathrm{~s}^{-1}$ for polystyrene film and $7.54 \times 10^{-3} \mathrm{~s}^{-1}$ for polysulfone film. One observes that the photoisomerization rates in solution and in polymer films are of the same order of magnitude. These results suggest that there is no significant influence of the polymer main chain structure and packing on the trans-cis photoisomerization process in solution as well as in polymer film. Similar observations have been made for other azobenzene-containing polymers. ${ }^{25,30}$ However a deviation from the first-order law was observed in the later stages of the photoprocess in polymer films and it has been explained by a retardation of cis isomer formation due to some restrictions in the chromophore mobility.

\section{Thermal cis-trans izomerization in polymer matrix}

The spectral changes show a recovery to the initial spectral pattern. The thermal reversion to the original trans form in polystyrene film was observed after about $230 \mathrm{~min}$ at $70{ }^{\circ} \mathrm{C}$. The thermally induced cis-trans isomerization of the azobenzene molecules incorporated in polymer films was monitored at different temperatures. Representative data are shown in Figure 5. One observes that the process occurring below $70{ }^{\circ} \mathrm{C}$ deviates from the first-order kinetics. In this case a biexponential equation 3 containing two first-order terms describes the kinetic behavior of the thermal recovery. ${ }^{31}$

$$
\left(\mathrm{A}_{\infty}-\mathrm{A}_{\mathrm{o}}\right) /\left(\mathrm{A}_{\infty}-\mathrm{A}_{\mathrm{t}}\right)=\alpha \exp \left(-\mathrm{k}_{2} \mathrm{t}\right)+(1-\alpha) \exp \left(-\mathrm{k}_{3} \mathrm{t}\right)
$$

where $\mathrm{k}_{2}$ and $\mathrm{k}_{3}$ are the rate constants of the fast and slowly isomerizing processes, respectively, and $\alpha$ the fraction of fast isomering species.

It is supposed that the biexponential equation 3 suggests two different local environments in which the thermal cis-trans isomerization takes place, namely one where a fraction of cis azo molecules quickly convert to trans species and another one where the remainder isomerizes more slowly. This fact seems to be in agreement with experimental data obtained for other azoaromatic polymer systems. ${ }^{29,31}$ The fast process can be ascribed to the trapping of cis chromophores in a strained environment, that determines their rapid return to trans species as compared to the relaxed cis isomers. The slow isomerization can be attributed to the cis species which are not environmentally stressed to isomerize. The slow isomerization process would depend on the coupling interaction between the azobenzene moieties and polymer segments and on the mobility of the polymer chain segments. ${ }^{32}$ The two rate constants for MAz containing polystyrene films were $1.34 \times 10^{-5} \mathrm{~s}^{-1}$ and $6.43 \times 10^{-4} \mathrm{~s}^{-1}$ at $50{ }^{\circ} \mathrm{C}$.

On the other hand the kinetics of the thermal cis-trans reaction in polystyrene films at $70{ }^{\circ} \mathrm{C}$ and higher could be satisfactorily described with equation 2 (Figure 5). The activation energy for the first process of the cis-trans recovery evaluated from Arrhenius plot, is lower for film samples $\left(\mathrm{E}_{\mathrm{a}}=15.55 \mathrm{kcal} \mathrm{mol}^{-1}\right)$ than that found in solution. Also the corresponding estimated preexponential factor $\left(\mathrm{Z}=3.3 \times 10^{6} \mathrm{~s}^{-1}\right)$ is also smaller. Such behavior can be explained by assuming that the structures of the cis isomers are different in solution and in polymer matrix. Also, we found out that the kinetics of thermal recovery in MAz containing polysulfone film at $65^{\circ} \mathrm{C}$ is also described by a first-order kinetics (Figure 5), with a rate constant of $4.34 \times 10^{-4} \mathrm{~s}^{-1}$.

These values of rate constants are similar in magnitude to those of other systems containing azobenzene units covalently bonded or incorporated in polystyrene. The rate constants corresponding to thermal isomerization of 2-ethoxyazobenzene or 2,2'-azonaphthalene were $1.41 \times 10^{-4}\left(55^{\circ} \mathrm{C}\right)$ and $1.33 \times 10^{-4} \mathrm{~s}^{-1}\left(45^{\circ} \mathrm{C}\right)$, respectively, ${ }^{33}$ while for 4-dimethylaminoazobenzene chromophore in polystyrene two rate constants were found out $2.50 \times 10^{-4}$ and $5.33 \times 10^{-5} \mathrm{~s}^{-1}\left(30^{\circ} \mathrm{C}\right)$, respectively. ${ }^{3}$

The trans-cis photoisomerization in polymer films was also performed by irradiation with $334 \mathrm{~nm}$ UV light. The changes in the electronic absorption spectra show similar trends as described above, the photoisomerization rate constant being $6.38 \times 10^{-3} \mathrm{~s}^{-1}$.

The back reaction process in MAz containing polymer films was also carried out by irradiation with blue light at $436 \mathrm{~nm}$ (Figure 6). The increase in intensity of the $\pi-\pi^{*}$ absorption was very quickly during irradiation and the absorption spectrum was completely restored to that of nonirradiated sample after only $360 \mathrm{~s}$. The corresponding cis-trans isomerization rate constant was 


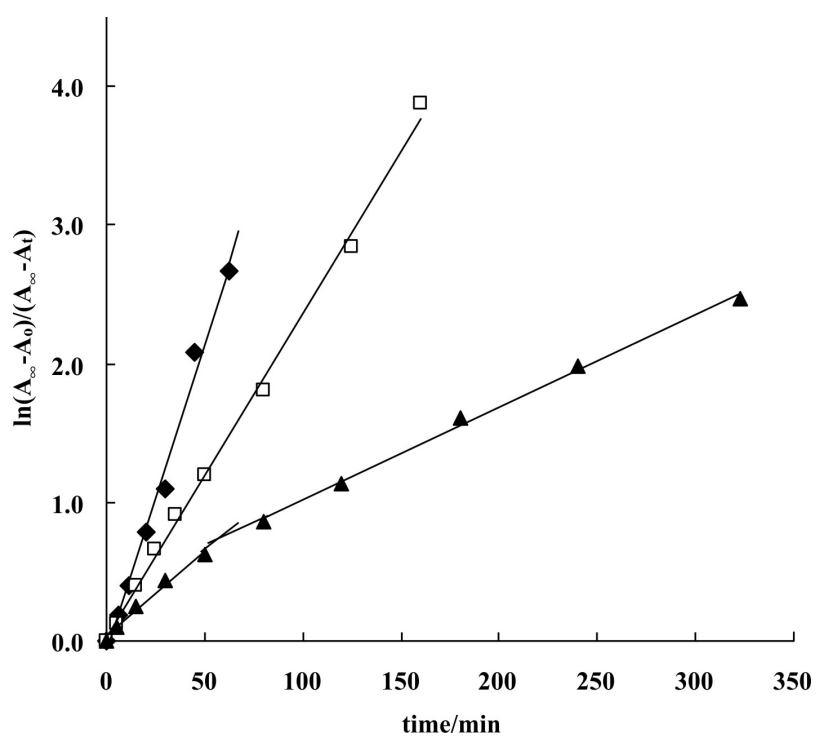

Figure 5. Kinetic data for cis-trans thermal isomerization of MAz in polymer films: $(\diamond)$ - Polystyrene $\left(70{ }^{\circ} \mathrm{C}\right)$; $(\square)$ - Polysulfone $\left(65^{\circ} \mathrm{C}\right)$; (A) - Polystyrene $\left(60{ }^{\circ} \mathrm{C}\right)$.

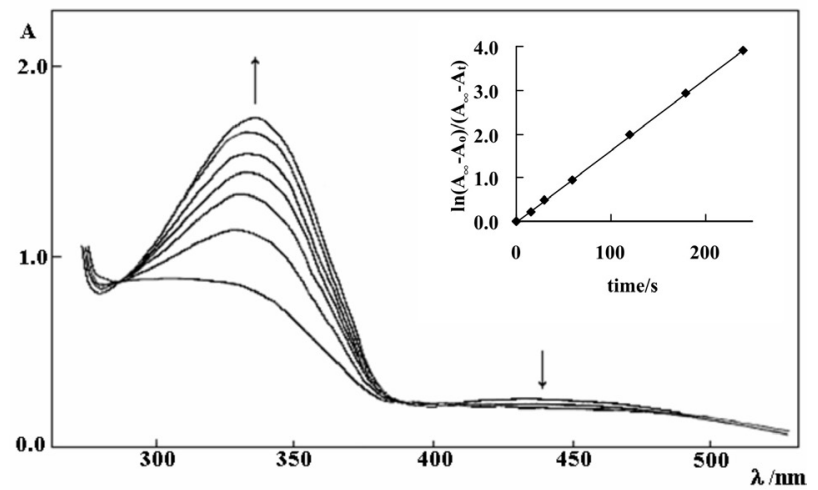

Figure 6. Progress of the absorption spectra during the irradiation with $436 \mathrm{~nm}$ light at room temperature for a film sample previously trans-cis isomerized. Inlet: Cis-trans isomerization kinetics. Arrows indicate the directional changes of the spectra. Irradiation times: 0, 10, 20, 30, 45, $90,360 \mathrm{~s}$.

found $3.41 \times 10^{-2} \mathrm{~s}^{-1}$. The recovery to the initial trans state in the absorption spectra and the presence of the isosbestic points show clearly that the blue light induces cis-trans isomerization process.

\section{Conclusions}

The isomerization behavior of 4 -( $\mathrm{N}$-maleimido) azobenzene embedded in polymer matrices in comparison with that of low molecular weight azobenzene compounds provided information regarding the isomerization mechanism in polymer films. The spectroscopic investigation of these systems showed trans-cis-trans isomerization of azobenzene chromophores in polymer matrix. The cis-trans relaxation occurred thermally or under visible light irradiation. Thermal isomerization of azobenzene chromophores in polymer films has been satisfactorily described by first-order kinetics at $70{ }^{\circ} \mathrm{C}$ and higher, while two first-order rate processes occur at temperatures below $70^{\circ} \mathrm{C}$. By irradiation with visible light at $436 \mathrm{~nm}$, the cis-trans process occurs very quickly (in $360 \mathrm{~s}$ ) in comparison with thermal relaxation (few days at $30{ }^{\circ} \mathrm{C}$ ). These results may be useful in design of new polymeric containing-azobenzene materials with enhanced photoresponsive properties and they' could be promising materials in some optical applications.

\section{References}

1. Kumar, G. S.; Azo Functional Polymers, Technomic Publ.: Lancaster, 1992, p. 158.

2. Xie, S.; Natansohn, A.; Rochon, P.; Chem. Mater. 1993, 5, 403; Natansohn, A.; Rochon, P.; Chem. Rev. 2002, 102, 4139.

3. Yamaki, S. B.; Oliveira, M. G. de; Atvars, T. D. Z.; J. Braz. Chem. Soc. 2004, 15, 253.

4. Izumi, M.; Teraguchi, R.; Nomura, T.; Masuda, T.; Macromolecules 2000, 33, 5347; Wang, D.; He, Y.; Deng, W.; Wang X.; Dyes Pigm. 2009, 82, 286.

5. Shi, Y.; Steier, W. H.; Lu, L.; Shen, M.; Dalton, L. R.; Appl. Phys. Lett. 1991, 58, 1131; Li, N.; Lu, J.; Xia, X.; Xu, Q.; Wang L.; Polymer 2009, 50, 428; Steter, J. R.; Pontolio, J. O; Campos, M. L. A. M.; Romero, J. R.; J. Braz. Chem. Soc. 2008, 19, 660.

6. Ghebremichael, F.; Kuzyk, M. G.; Lackritz, H. S.; Prog. Polym. Sci. 1997, 22, 1147.

7. Delaire, J. A.; Nakatani, K.; Chem. Rev. 2000, 100, 1817.

8. Alam, M. Z.; Ohmachi, T.; Ogata, T.; Nonaka, T.; Kurihara, S.; Opt. Mater. 2006, 29, 365.

9. Seki, T.; Skuragi, M.; Kawanishi, Y.; Suzuki, T.; Tamaki, T.; Fukuda, R.; Ichimura, K.; Langmuir 1993, 9, 211.

10. Andruzzi L.; Altomare, A.; Ciardelli, F.; Solaro, R.; Hvilsted, S.; Ramanujam, P. S.; Macromolecules 1999, 32, 448; Pereira, W. S.; Freire, R. S.; J. Braz. Chem. Soc.; 2006, 17, 832.

11. Kumar, G. S.; Neckers, D. C.; Chem. Rev. 1989, 89, 1915.

12. Rau, H. In Photochemistry and Photophysics; Rabek, J. F., ed.; CRC Press: Boca Raton, 1990, vol. 2, p.119.

13. Rabek, J. F.; Mechanisms of Photophysical Processes and Photochemical Reactions in Polymers, Wiley: Chichester, 1987, p. 756.

14. Sekkat, Z.; Knoesen, A.; Lee, V. Y.; Miller, R. D.; J. Phys. Chem. B 1997, 101, 4733; Pavinatto, F. J.; Barletta, J.Y.; Sanfelice, R. C.; Cardoso, M. R.; Balogh, D. T.; Mendonça, C. R.; Oliveira Jr. O. N.; Polymer 2009, 50, 491; Yang, P. C.; Wu, M. Z.; Liu, J. H.; Polymer 2008, 49, 2845.

15. Strat, M.; Delibas, M.; Strat, G.; Hurduc, N.; Gurlui, S.; J. Macromol. Sci., Part B: Phys. 1998, 37, 387; Cerruti, P.; Borbone, F.; Carella, A.; Malinconico, M.; Mormile, P.; Petti, L.; Rippa, M.; Roviello, A.; Laurienzo P.; Polymer 2009, 50, 1645. 
16. Yaroshchuk, O.; Kiselev, A. D.; Zakrevskij, Y. Stumpe, J.; Lindau J.; Eur. Phys. J. E 2001, 6, 57.

17. Eisenbach, C. D.; Ber. Bunsenges. Phys. Chem. 1980, 179, 2489.

18. Barrett, C. J.; Natansohn, A.; Rochon, P.; Macromolecules 1994, 27, 4781

19. Royal, J. S.; Victor, K. G.; Torkelson, J. M.; Macromolecules 1992, 25, 729 .

20. Cunha, S.; Rodovalho, W.; Azevedo, N. R.; Mendonça, M. de O.; Lariucci C.; Vencato, I.; J. Braz. Chem. Soc. 2002, 13, 629; Dias, L. C.; J. Braz. Chem. Soc. 1997, 8, 289; Dick D. P.; Burba P.; J. Braz. Chem. Soc. 1999, 10, 146.

21. Altomare, A.; Carlini, C.; Ciardelli, F.; Solaro, R.; Polymer 1983, 24, 95.

22. Whitten, D. G.; Wildes, P. D.; Pacificci, J. G.; Irick, G.; J. Am. Chem. Soc. 1971, 93, 2004; Liu, Z. F.; Morigaki, K.; Enomoto, T.; Hashimoto, K.; Fujishima, A.; J. Phys. Chem. 1992, 96, 1875; Liu, W.; Bian, S.; Li, L.; Samuelson, L.; Kumar, J.; Tripathy, S.; Chem. Mater. 2000, 12, 1577.

23. Naito, T.; Horie, K.; Mita, I.; Eur. Polym. J. 1990, 26, 1295.
24. Altomare,A.; Ciardelli, F.; Tirelli, N.; Solaro, R.; Macromolecules 1997, 30, 1298.

25. Airinei, A.; Buruiana E. C.; J. Macromol. Sci., Part A: Pure Appl. Chem. 1994, 31, 1233.

26. Horie, K.; Mita, I.; Adv. Polym. Sci. 1989, 88, 77.

27. Suzuki, I.; Ishizaki, T.; Inoue, H.; Anzai J.; Macromolecules 2002, 35, 6470.

28. Wang, C.; Weiss, R. G.; Macromolecules 2003, 36, 3833.

29. Ueda, M.; Kim, H. B.; Ikeda, T.; Ichimura K.; Chem. Mater. 1992, 4, 1229.

30. Ruslim, C.; Ichimura, K.; Macromolecules 1999, 32, 4254.

31. Eisenbach, C. D.; Makromol. Chem. 1979, 180, 565.

32. Ho, M. S.; Natansohn, A.; Rochon, P.; Macromolecules $\mathbf{1 9 9 5 ,}$ 28, 6124 .

33. Priest, W. J.; Sifain, M. M.; J. Polym. Sci., Part A: Polym. Chem. 1971, 9, 3161.

Received: July 2, 2009

Web Release Date: December 3, 2009 